\title{
Humidification on Ventilated Patients: Heated Humidifications or Heat and Moisture Exchangers?
}

\author{
F. Cerpa ${ }^{1}$, D. Cáceres ${ }^{1}$, C. Romero-Dapueto ${ }^{1}$, C. Giugliano-Jaramillo ${ }^{1}$, \\ R. Pérez ${ }^{1}$, H. Budini ${ }^{1}$, V. Hidalgo ${ }^{1}$, T. Gutiérrez ${ }^{1}$, J. Molina ${ }^{2}$ and J. Keymer ${ }^{*}{ }^{1}$
}

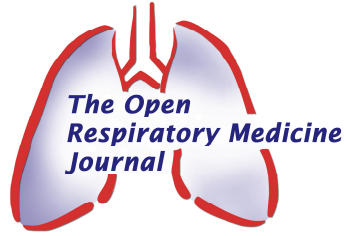

\author{
${ }^{I}$ Servicio de Medicina Física y Rehabilitación, Clínica Alemana de Santiago, Santiago, Chile \\ ${ }^{2}$ Escuela de Kinesiología, Universidad del Desarrollo, Santiago, Chile
}

\begin{abstract}
The normal physiology of conditioning of inspired gases is altered when the patient requires an artificial airway access and an invasive mechanical ventilation (IMV). The endotracheal tube (ETT) removes the natural mechanisms of filtration, humidification and warming of inspired air. Despite the noninvasive ventilation (NIMV) in the upper airways, humidification of inspired gas may not be optimal mainly due to the high flow that is being created by the leakage compensation, among other aspects. Any moisture and heating deficit is compensated by the large airways of the tracheobronchial tree, these are poorly suited for this task, which alters mucociliary function, quality of secretions, and homeostasis gas exchange system. To avoid the occurrence of these events, external devices that provide humidification, heating and filtration have been developed, with different degrees of evidence that support their use.
\end{abstract}

Keywords: Air humidification, Humidification devices, humidification IMV, humidification NIMV.

\section{INTRODUCTION}

The human airway has an important role in heating and humidification of the inspired gas [1]. During spontaneous breathing, inspiratory gases are usually heated and humidified in the nasal cavity and pharynx [2]. The normal physiology of conditioning gas is altered when the patient requires an artificial airway, intubation eliminates the natural mechanisms of filtration, humidification, and warming of inspired air [3]. The humidification of inspired gas is mandatory for all mechanically ventilated patients, however, the debate about the ideal humidification continues today [4].

NIMV supplies dry and cold gas through the upper airway causing dryness of the mucosa and respiratory dysfunction. Leakage compensation applied by NIMV creates high flow throughout the respiratory cycle, which contributes to the loss of heat and humidity [5]. Although in NIMV the upper airway is preserved, humidification during NIMV might not be optimal due to the greater flow delivered, thus producing an increase in mucous viscosity and secretion retention, these conditions that increase the risk of obstruction of the upper airways [6].

During NIMV, active humidification is recommended to improve patient comfort [7]. But in which patients, it provides better evidence and Is it always necessary in hospitalized patients?

*Address correspondence to this author at the Servicio de Medicina Física y Rehabilitación, Clínica Alemana de Santiago, Avenida Vitacura 5951, Vitacura, Santiago, Chile; Tel: +56222101421; Fax: +56222101421;

E-mail: jkeymer@alemana.cl

\section{PHYSIOLOGICAL CONCEPTS}

\subsection{Humidification}

Humidity refers to the quantity of water vapor in a gaseous environment [4] and it depends on the temperature of the gas and it can be expressed in two ways, as absolute humidity and relative humidity. The absolute humidity $(\mathrm{AH})$ is the amount of water in a given volume of gas usually expressed in $\mathrm{H} 2 \mathrm{O} \mathrm{mg} / \mathrm{L}$ volume $[4,8]$. The relative humidity $(\mathrm{RH})$ is the amount of water vapor in a volume of gas, expressed as a percentage of the amount of water vapor required to fully saturate the same volume of gas at the same temperature and pressure [4].

If atmospheric air is at $20^{\circ} \mathrm{C}$, and has an $\mathrm{AH} \mathrm{H} 2 \mathrm{O}$ of about $10 \mathrm{mg} / \mathrm{L}$ water and $\mathrm{RH}$ of 55 to $60 \%$. As this air passes through the nose and upper respiratory tract, it humidifies and heats the air [4]. This occurs thanks to the fact that in nasopharynx the inspired gases are exposed to a highly vascularized moist mucous membrane [9]. The respiratory mucosa is lined by ciliated columnar pseudostratified epithelium and numerous goblet cells, these cells and submucosal glands are responsible for maintaining the mucosal layer that serves as a trap for the pathogens and as an interface for the exchange of moisture. At the level of the terminal bronchioles, the epithelium becomes a simple cubic type with minimum goblet cells and few submucosal glands. Therefore, the capacity of these pathways to perform the same level of humidification than the upper airway is limited $[8,10]$.

The movement of the cilia is called metachronalciliary; the beat frequency is directly proportional to the temperature $\left(\mathrm{t}^{\circ}\right)$ and it is normal that at $37^{\circ} \mathrm{C}$ it is $750 \mathrm{~b} / \mathrm{min}$, but at $40^{\circ} \mathrm{C}$ it increases to $1100 \mathrm{~b} / \mathrm{min}$. Excessive moisture affects ciliary 
function, since it increases the volume of secretions due to its low viscosity and risk of atelectasis by plugging the airway [11]. This explains why at a temperature above $37^{\circ} \mathrm{C}$ and $100 \%$ gas saturation produces a condensation of the gas, thus causing a reduction in mucus viscosity and an increase in the thickness of the pericellular liquid, which may be too liquid to be coupled properly to the tips of the cilia, thus affecting mucociliary transport $[12,13]$.

As the air moves forward through the respiratory tract, it will be thermo-humidified, at the middle of the trachea the temperature and the $\mathrm{AH}$ reaches approximately $34^{\circ} \mathrm{C}$ and 34 to $38 \mathrm{mg} \mathrm{H} 2 \mathrm{O} / \mathrm{L}$ respectively [14]. The point at which the gas reaches $37^{\circ} \mathrm{C}$ and a relative humidity of $100 \%$ (which corresponds to an absolute humidity of $44 \mathrm{mgH} 2 \mathrm{O} / \mathrm{L}$ ), it is known as the limit of isothermal saturation, which is about 5 $\mathrm{cm}$ below the carina during quiet breathing between the third and the fifth generation of the bronchial tree $[14,15]$. This provides optimal conditions for gas exchange in the alveolarcapillary membrane [4]. Humidity and temperature are constant below the limit of isothermal saturation [14].

The upper airway delivers $75 \%$ of the heat and humidity delivered to the alveoli. If the physiological conditions change, either by having an ETT during the IMV or when changing the flow and pressure conditions during NIMV, there is not an adequate system of humidification for our patients. The point of isothermal saturation could be affected, any moisture and heating deficit is compensated by the large airways of the tracheobronchial tree, which are unsuitable for this task, thus altering the mucociliary function, quality of secretions, and the homeostasis system gas exchange.

\subsection{Humidification Devices}

Humidifiers are devices that add water molecules, gas and temperature. They are classified as active if they have external sources of heat, water and flow, and passive if they use temperature and hydration from the exhaled gas from patients [16]. See Table 1.

\subsection{Active Humidifiers}

These types of humidifiers are divided into several categories: bubble humidifiers, waterfall humidifiers, bypass humidifiers and shirt humidifiers [8]. Of the active humidification systems, the bypass is the most widely used today in the ICU, they are applied in both, in mechanical ventilation and noninvasive ventilation [7]. The gas that goes to the patient passes over the surface of the heated water, which causes the humidification to come close to $100 \% \mathrm{RH}$ and can deliver up to $44 \mathrm{mg} / \mathrm{L}$ of $\mathrm{AH}[17,18]$.

The water is heated via heating base, which transmit heat by convection from the metal of the bases. It is selfregulating by a servomechanism and consist of: a heating cable, (which maintains the temperature of gas in the circuit, thus preventing condensation in the piping and the probability of bacterial colonization), a cable with two temperature sensors, which are locked at the output of the humidifier, and a Y-piece (near the patient) to servo-control the temperature of the system $[18,19]$. In most modern devices, the temperature is preset at $37^{\circ} \mathrm{C}$ [20]. This system maintains control of the gas temperature to the patient, regardless of changes in the gas flow or water level in the reservoir, despite having a slow time of reaction [21]. The water that condenses the pipes is considered contaminated, and should not be returned to the humidifier [19]. The main problem with this device is that it does not filter particles [22].

\subsection{Passive Humidifiers}

Are disposable heat and moisture exchangers (HME), some with a particle filter. They are lightweight, inexpensive and easy to use with standard connectors for IMV [23]. They contain a high contact surface of paper, with compressed metallic elements which capture particles of exhaled water vapor and heat, holding and releasing it in the next inspiration. To fulfill this function, the HME can be Hydrophobic (HMEF, Heat-and-Moisture Exchanger Filter) Hygroscopic (HHME, Hygroscopy Heat-and-Moisture Exchanger) or both with filter (HHMEF, Hygroscopy Heatand-Moisture Exchanger and filter). This data are shown in

Table 1. Advantages and disadvantages of HH and HME.

\begin{tabular}{|c|c|c|}
\hline \multirow{4}{*}{ Active } & Universal application & Cost \\
\hline & Alarms & Condensation \\
\hline & Wide ranges of temperature and humidity & Risk of contamination \\
\hline & Reaches the maximum absolute humidity & no Filter \\
\hline \multirow[b]{3}{*}{ Passive } & Cost & Does not apply to all patients \\
\hline & Passive operation & Increased dead space \\
\hline & User friendly & Increased resistance \\
\hline
\end{tabular}


Table 2. Types of heat-and-moisture exchanger.

\begin{tabular}{|c|c|c|}
\hline & Function & Absolute Humidity \\
\hline \hline HME & Hydrophobic & $10-14 \mathrm{mgH} 2 \mathrm{O} / \mathrm{L}$ \\
\hline HMEF (Heat-and-Moisture Exchanger Filter): & Hydrophobic + Filter & $18-28 \mathrm{mgH} 2 \mathrm{O} / \mathrm{L}$ \\
\hline HHME (Hygroscopy Heat-and-Moisture Exchanger): & Hydrophobic + Hygroscopic & $22-34 \mathrm{mgH} 2 \mathrm{O} / \mathrm{L}$ \\
\hline HHMEF (Hygroscopy Heat-and-Moisture Exchanger): & Hydrophobic + Hygroscopic + Filter & $23-35 \mathrm{mgH} 2 \mathrm{O} / \mathrm{L}$ \\
\hline
\end{tabular}

Table 2. Hygroscopic is an adjective of a compound chemical material, which absorbs moisture from the air. The aluminum material of this device quickly exchanges temperatures when expiration condensation is formed between the layers of this material. The retained heat and moisture are returned during inspiration. Adding a fibrous element helps retain moisture and reduces the accumulation of condensation in the dependent position of the device [24, 25]. Hydrophobic is an adjective for those substances or elements that repel water and cannot mix or absorb. They use a paper or polypropylene treated with calcium or lithium chloride, to increase moisture conservation and repel water that is not absorbed [26]. It is Important to mention that these devices also function as a bacterial filter [17]. The HME are installed between the Y-piece of the patient, which can increase the resistance to airflow, not only during inspiration, but also during expiration. The minimum resistance to the flow is 0.5 to $3.6 \mathrm{~cm} \mathrm{H} 2 \mathrm{O} / \mathrm{L} / \mathrm{sec}[27,28]$. It is important to take into account the dead space produced by these devices, which can be variable. Among different devices according to some measurements, it can reach $95 \mathrm{~mL}$ [29, 30]. Passive humidifiers should never be used in conjunction with active humidifiers [31].

If water or fluids occlude the HME, the patient is not ventilated properly, and may be unable to fully exhale during ventilation with positive pressure [32]. Studies recommend using HHMEF for their hydrophobic, hygroscopies and filter characteristics, as shown in Table 2 [9].

\section{WHAT IS THE MINIMUM VALUE OF MOISTURE THAT A DEVICE MUST DELIVER?}

The American National Standards Institute (ANSI) and the American Association for Respiratory Care (AARC) recommend an $\mathrm{AH} \geq 30 \mathrm{mg} \mathrm{H} 2 \mathrm{O} / \mathrm{L}$ for the inspired air during mechanical ventilation $[16,33]$, while the ISO (International Organization for Standardization) prefer $\mathrm{AH}$ values $\geq 33 \mathrm{mg}$ $\mathrm{H} 2 \mathrm{O} / \mathrm{L}$ [34]. It is important to consider that the performance specifications provided by the manufacturers of HMEs are based on in vitro measurements when delivering moisture, using the ISO 9360 method [7, 35]. However the in vivo performance of HMES may differ from the manufacturer's specifications when defining the ability to heat and humidify, these configurations do not fully reflect the physiology of human respiration $[7,36]$. An important aspect is that we have to know the performance of the devices we use in our unit. In a study by Lellouche et al. in 2009 [29] tested $32 \mathrm{HME}$ and showed that only $37.5 \%$ had a good performance $(>$ or $=30 \mathrm{mg} \mathrm{H} 2 \mathrm{O} / \mathrm{L})$, while $25 \%$ did poorly $(<25 \mathrm{mg} \mathrm{H} 2 \mathrm{O} / \mathrm{L})$. The difference in values between their measurements and the data supplied by the manufacturer regarding the humidification was $3.0 \pm 2.7 \mathrm{mg} \mathrm{H} 2 \mathrm{O} / \mathrm{L}$, that is why we must check if the devices at our units have been tested and if they meet the standard, regardless of what the manufacturer states. Restrepo et al. [7] states that the device to use, either active or passive, must provide a moisture level of $33 \mathrm{mg} \mathrm{H} 2 \mathrm{O} / \mathrm{L}$ and $44 \mathrm{mg} \mathrm{H} 2 \mathrm{O} / \mathrm{L}$ and a temperature between $34^{\circ} \mathrm{C}$ and $41^{\circ} \mathrm{C}$ with a $\mathrm{RH} 100 \%$ to prevent drying of secretions in the artificial airway.

\section{HUMIDIFICATION IN IMV, WHICH DEVICE CAN WE USE?}

The Mechanical ventilation delivered through a tracheal tube (ETT) to critically ill patients, requires appropriate heating, moistening and filtering of the airway in order to counteract bypassing of the upper respiratory tract due to the use of an ETT [37]. Any moisture deficit must be offset by the large airways of the tracheobronchial tree, which are poorly suited for this task, the gas with low $\mathrm{RH}$ rapidly absorbs moisture from the tracheobronchial mucosa and secretions in the airway, this can result in dry secretions, plugging with mucus, and obstruction of the airways [38]. The heating and humidifying of inspiratory gas, with different devices, can prevent complications associated with dryness of the respiratory mucosa, which can lead to the occlusion of the ETT [39]. That is why the humidification is recommended in all patients receiving IMV with a level of evidence $1 \mathrm{~A}$ [7].

There are variables that could affect us in the moistening, and can influence the choice of the appropriate humidifying device:

\subsection{Ambient Air Temperature}

Lellouche et al. [40] measured two passive and one active/passive (Hudson Heat Teleflex Humid-Medical) HMEs, at three different environment temperature (22 to $30^{\circ} \mathrm{C}$ ), and concluded that there is a negligible effect of room temperature in the moisture delivered by HMEs, since these devices can be used to provide adequate moistening in different climates.

\subsection{Minute Ventilation (VE)}

Various studies that measure the impact of tidal volume (VT), respiratory rate (RR) and minute ventilation (VE) in humidification, have used high VT from 0.5 to $1.0 \mathrm{~L}$ and higher VE between 10 and $20 \mathrm{~L} / \mathrm{min}$ [41]. A randomized controlled trial that compared HME with hydrophobic properties, an HME with hydrophobic and hygroscopic properties compared and $\mathrm{HH}$, with minute ventilation of 10.8 
$\mathrm{L} / \mathrm{min}, 11.6 \mathrm{~L} / \mathrm{min}$ and $10.2 \mathrm{~L} / \mathrm{min}$, showed that after 72 hours, the internal diameter of the ETT had decreased 6.5 $\mathrm{mm}$ with hydrophobic HME, $2.5 \mathrm{~mm}$ with hygroscopic and hydrophobic HME, and $1.5 \mathrm{~mm}$ with an $\mathrm{HH}$ [42]. This would allow the conclusion that in patients with high VE (over $10 \mathrm{~L} / \mathrm{min}$ ), we should choose a $\mathrm{HH}$. In a recent study Lellouche et al. [40] they reached the conclusion that VE variation was not significant in the HME humidification performance when using VT of 0.5 and $0.65 \mathrm{~L}$, with a respiratory rate of 20 to 30 breaths/minute, and with VE of 10 and $20 \mathrm{~L} / \mathrm{M}$, respectively. An important aspect to consider is that the strategies mentioned above do not correlate with lung protective strategies for IMV. The current guidance of ventilation strategies is based on predicted body weight according to height, were the use of ventilation is recommended between $6 \mathrm{~mL} / \mathrm{kg}$ and $8 \mathrm{~mL} / \mathrm{kg}$, even further reduced to a minimum of $4 \mathrm{~mL} / \mathrm{kg}$ when possible [43]. As Antony R Wilkes [41] says, the manufacturers are forced to declare the range of values of VT in which the HME can be used, therefore we suggest you to consider this information when you have to acquire these devices in your unit.

\subsection{Dead Space}

One of the drawbacks of using HMEs, and which may restrict their use, is that due to its large internal volume, increase the dead space of the circuit, which in turn can increase minute ventilation, carbon dioxide arterial pressure $\left(\mathrm{PaCO}_{2}\right)$ and work of breath during pressure support ventilation [44]. This increase in dead space decreases alveolar ventilation, and produces an increase in arterial $\mathrm{PaCO} 2$, in order to maintain the same level of alveolar ventilation. A ventilatory strategy would be to increase the tidal volume, thereby exposing patients to induced lung injury by volume [8]. This has a great relevance in patients with Acute respiratory distress syndrome (ARDS), because as described above it is important to look ventilatory strategies of $4 \mathrm{~mL} / \mathrm{kg}$ to $6 \mathrm{~mL} / \mathrm{kg}$ [43]. In the study by Moran et al, 2006 [45], in patients with acute lung injury (ALI) and ARDS were ventilated with HME devices in which $\mathrm{PaCO} 2$ was measured, and then maintaining the same VT, positive end expiratory pressure (PEEP), RR and $\mathrm{FiO} 2$ were changed to a $\mathrm{HH}$ device, with these they saw that $\mathrm{PaCO} 2$ decreased from $46+/-9$ to $40+/-8 \mathrm{mmHg}$. Prat et al. [46] showed a decrease in $\mathrm{PaCO} 2$ levels of $17 \mathrm{mmHg}$ in patients with ARDS when a HH are used instead of HME. This will be related to a difference in the dead space of $95 \mathrm{ml}$ between devices $[8,46]$. The reduction in dead space using $\mathrm{HH}$ decreases $\mathrm{PaCO} 2$ and most importantly, if isocapnic conditions are maintained through a VT reduction strategy, which would improve lung compliance and would reduce the plateau pressure [45].

\subsection{Quantity and Quality of Airway Secretions}

The presence of biofilm on the inner wall of the endotracheal tube is represented, formed by microorganisms that produce exopolysaccharides whose function is to protect from antibiotics the immune system [47, 48]. This biofilm provides the basis for the accumulation of secretions in the tube, with the risk of further obstruction in the presence of secretions adhered to this layer, resulting in reduced lumen at about $7 \%$ without observing an occlusion if using a suitable humidification. Poor moistening is associated with a high incidence and greater degree of ETT obstruction by secretions [49]. A proposal for the evaluation of this biofilm it is shown in a study by Coppadoro et al. [50] through MicroCT, where exhibits the layer of biofilm and also stablishes that the volume of secretions in the ETT is not associated with microbial colonization. With these data, we can say that there is more than one risk factor that can facilitate ETT obstruction. Branson et al. [51], based on a series of studies, proposes some contraindications for the use of HME, among them mentions: the presence of hematic secretions with risk of HME occlusion, which would increase the work breathing and adherent secretions, so more humidification is needed to liquefy secretions and decrease the risk of mucus plugging and airway occlusion.

\subsection{Gas Exhaled Temperature}

In hypothermia patients, the use of $\mathrm{HH}$ is recommended because it maintains a suitable temperature in the respiratory tract and prevents heat loss to the environment, taking a marginal role $(10 \%)$ in the elevation of body temperature [52].

\subsection{Mechanical Ventilation-Associated Pneumonia (VAP)}

Various authors since the 90 's, have attempted to establish the relationship between the type of humidifier and the rate of mechanical ventilation-associated pneumonia. In this search, there have been randomized trials [53-55], where Kola et al. [55] compared the hygroscopic HME and HH, wherein show among other causes of VAP as the oropharyngeal aspiration, condensation deposited in ventilator circuits, that by itself is a source of infection due to high levels of colonization in the system, especially after seven or more days of IMV. At this point we should consider incorporating heating cable circuits to minimize the possibility of condensation on the circuit and prevent colonization produced by the above mentioned condensation. Other authors, Lorente et al. 2006 [56], in the search to establish guidelines that lead to reduced VAP, state that in periods of IMV at least five days using $\mathrm{HH}$, the incidence of VAP is reduced when compared to HME, considering that previous studies showed patients data with shorter periods of IMV, and with new measures such as incorporating heating cables circuits and servo controlled water chambers, optimum temperature and moisture levels are achieved for the operation of the mucociliary escalator.

In a meta-analysis of Ilias et al. (2007) [57], about the benefits of HME compared with HH reduced: the incidence VAP, mortality, length of ICU stay, duration of IMV, ETT occlusions and costs associated with humidifier device. They conclude that the available evidence does not allow establishing differences in the performance of HME and $\mathrm{HH}$ in relation to the incidence of VAP, neither in mortality, length of ICU stay, duration of IMV or obstruction episodes. More recently, M. Help-Martins et al. 2012 [58] found that there are no significant differences in the use of $\mathrm{HH}$ and HME on the incidence of VAP, IMV days, days of ICU stay and overall mortality rate. In the same line, these authors 
report in a recent meta-analysis [59] that there is insufficient evidence to recommend the use of HME for the prevention of VAP, due to methodological limitations in the metaanalysis as sample size, lack of any description of randomization not mentioned in blind studies, etc. suggesting with a degree of uncertainty that the HME does not decrease the incidence of VAP.

In summary, all patients with IMV should use some moistening and heating system. Based on some variables such as those mentioned above and the available evidence, it is recommended to use $\mathrm{HH}$ in patients with certain clinical conditions, since the HME have certain contraindications [7, 8, 51], which are detailed below:

1. Patients with hypothermia (body $\mathrm{T}^{\circ}<32^{\circ} \mathrm{C}$ ), since HME occupy temperature and moisture of exhaled gas, if this is decreased, the moisture inspired will also decrease.

2. Patients with hematic secretions, due to risk of coagulation, they may occlude ETT and/or HME, which would increase work of breathing.

3. Patients with adherents and/or copious secretions, we must deliver high humidity (44 mg/L and 100\% RH), to prevent the inspired gas from capturing heat and moisture of large caliber airway drying secretions, altering mucociliary belt, and producing mucus plugging of the airways.

4. Patients with leaking air, with an exhaled VT less than $70 \%$ of VT inspired, such as bronco pleural fistula, the entire volume of exhaled gas does not enter the HME, thus losing heat and humidity.

5. Patients with low VT, with protective ventilation strategies (4-6 $\mathrm{ml} / \mathrm{kg}$ ), because they contribute to increased dead space, and increase levels of $\mathrm{PaCO} 2$.

6. Patients with high values of minute volume $(>10$ $\mathrm{L} / \mathrm{min}$ ).

\section{IS NECESSARY HUMIDIFICATION IN NIMV?}

Evidence supports the use of NIMV in the management of acute respiratory failure (ARF) to avoid endotracheal intubation in patients with exacerbations of COPD or acute cardiogenic pulmonary edema, and immunocompromised patients as well as to facilitate extubation in patients with COPD [60]. Although there are several aspects that provide us a better patient-ventilator synchrony, and thus better adherence and success of NIMV, there is a lack of evidence that improved patient-ventilator synchrony is related to greater success of NIMV. However, as far as the patientventilator interaction, dyspnea and comfort are related, no one can argue against efforts to improve the synchrony during NIMV [61]. One aspect to consider is the moistening in patients who are undergoing NIMV. Inspiratory gases delivered by mechanical ventilators in ICU are dry, breathing rate is high, and mouth breathing is common during NIMV [62]. In the presence of mouth leaks with a nasal interface, the unidirectional flow dries upper airway and increases nasal airway resistance. When the upper airway is dried, increases patient discomfort, and may affect tolerance to NIMV [63].
Improper gas conditioning has been associated with anatomical and functional impairment of nasal mucosa (ciliary activity, mucus secretion, local blood flow, nasal resistance) [64]. Epithelial metaplasia and keratinization changes of nasal submucosa have been reported in patients with home NIMV when the level of humidification is inadequate for long periods of time [65].

Especially when gas without humidifying is used in NIMV, the upper airway can suffer mucosal dryness and respiratory dysfunction. Leakage compensation applied by NIMV deliver high flows throughout the respiratory cycle, which contributes to the loss of heat and humidity $[14,66]$.

A recent study found that even with the same configuration of the $\mathrm{HH}$, the $\mathrm{AH}$ varied between subjects, as well as increased inspiratory gas leak in some patients, $\mathrm{AH}$ decreased. The oral breathing decreased oral moisture and aggravated the feeling of dryness in patients [66].

The use of domiciliary NIMV for a few hours a day is widely used in different pathologies, although there are no general recommendations or guidelines for humidification during home NIMV [66], a 40-60\% of nasal CPAP users with obstructive sleep apnea syndrome (OSA) reported nasal congestion, dry mouth and throat pain after breathing cold and dry air [67], which explains in detail the nasal discomfort during CPAP treatment [68]. $\mathrm{RH}$ decrease can be attenuated significantly through thermal and humidification of inspired air, even during periods of mouth leak in patients with OSA [69]. Based on this, the American Academy of Sleep Medicine has recommended the use of $\mathrm{HH}$ to improve adaptation and adherence to CPAP as a standard practice [63].

In hospitalized patients there is more controversy whether humidification is routinely required during NIMV in acute patient care [14, 70]. Richard Branson et al. [14] says that the controversy continues about whether if routinely supplemental humidification is required during NIMV in acute patients. Gas law principles and clinical experience suggest that humidification can be used according to the patient's comfort and NIMV duration, and concludes that there is insufficient evidence to support the routinary use of active humidification during NIMV. Dean R. Hess [70] based on his personal experience in patients with ARF, states that an $\mathrm{HH}$ improves comfort and tolerance to NIMV, and produces less dryness of upper airway. Humidification level does not need to be so great as to an intubated patient; $100 \%$ of relative humidity and around $30^{\circ} \mathrm{C}$ is usually sufficient, higher temperatures may be less comfortable during NIMV.

Esquinas et al. [64] says that the analysis of the need for humidification during NIMV should clearly take into account the following parameters: Air leaks; NIMV interface; mechanical ventilator type; room temperature; inhaled gas temperatures and chamber vaporization; air flow and inlet pressure of the humidification system and humidification system type. And according to early observed histopathological changes in nasal mucosa, by the author in a study not yet published, in four patients with ARF, which are treated for seven days with NIMV without a humidification system, suggests that these nasal mucosa changes are relatively produced after starting NIMV in an acute situation, 
and that humidification should be considered even when a short term NIMV use is expected.

\section{ACTIVE OR PASSIVE NIMV HUMIDIFICATION?}

Jaber et al. refer that minute volume (VE) was significantly greater with $\mathrm{HME}$ than with $\mathrm{HH}$, this increase in VE was the result of increased respiratory rate with HME than with $\mathrm{HH}$, and $\mathrm{PaCO}_{2}$ was significantly greater with HME than with $\mathrm{HH}$, and concludes that during NIMV, increased dead space with HME can negatively affect ventilatory function and gas exchange, this may decrease the effectiveness of NIMV in patients with ARF [71].

Recent recommendations favor the use of heated humidifiers $(\mathrm{HH})$ during NIMV [7, 72], reducing nasal resistance, helping expectoration and improving adhesion and comfort, especially in patients with bronchial secretions [72]. HME is not recommended in NIMV, because dead space of the device has a negative impact on $\mathrm{CO}_{2}$ elimination and minute ventilation in patients treated with NIMV in ICU, this is more evident in hypercapnic patients [72, 73] also, there has been seen that it increases work in breathing [65, 71]. Restrepo et al. [7] supports this by saying that the active humidification is suggested for NIMV, because it can improve adherence and patient comfort (2B level evidence), and adds that the use of an HME is contraindicated in patients in NIMV (2C level evidence) with great mask leaks, because the patient does not exhale sufficient VT to replace heat and humidity to an adequate inspired gas. However a recent multicenter randomized controlled trial of 2014, Lellouche F. et al. [62] says that no short-term physiological benefits of $\mathrm{HH}$ were observed, compared with HME during NIMV, with "ICU ventilators" (bi branch) and no differences in the rate of intubation were found, thus concluding that the physiological effects may have been mitigated by leaks or other clinically important factors. Therefore states not to support the recent recommendation for the use of $\mathrm{HH} \mathrm{v/s}$ HME during NIMV with "ICU ventilators ".

We believe that in the application of NIMV, the type of ventilators takes an important role in the decision of the humidifier to be used. For a single branch turbine ventilator and with leakage compensation, it would be considered the use of $\mathrm{HH}$ in patients undergoing periods greater than $24 \mathrm{hrs}$ of NIMV to enhance the feeling of oral dryness and tolerance as recommended Oto in 2014 [66]. It is also important to consider the recommendations of Esquinas et al. [64] in terms of the factors involved in selecting the type of humidification to use such as; air leakage, interface type, type of ventilator, ambient temperature, inhaled gas temperature among others. Taking into consideration when using HME in single-branch NIMV, there must be taken into account where the exhalatory port is in the system.

\section{CONCLUSION}

Humidification of the airway is required in all patients with artificial airway and/or connected to IMV (1A evidence). Humidification devices can be $\mathrm{HH}$ or HME, being the clinical characteristics the ones that determine which device should be chosen. It is important to select the right system to avoid the complications of deficient humidification, such as dryness of the respiratory mucosa, damage to the epithelium of the respiratory tract and airway obstruction by secretions. This entails increased respiratory effort and alteration of the homeostasis gas exchange system.

During NIMV an inadequate gas conditioning has been associated with anatomical and functional impairment of the nasal mucosa. It is suggested the use of active humidification (2B evidence), while the use of passive humidification is not recommended ( $2 \mathrm{C}$ evidence). However recent publications using ICU ventilators are disagree with these recommendations.

We believe that to choose the type of humidifier to be used during NIMV, there are some aspects that must be taken into consideration such as the type of ventilator, the interface type and leakage, among others, that could favor the use of $\mathrm{HH}$ over HME to improve the tolerance and patient comfort.

\section{CONFLICT OF INTEREST}

The authors declare that there are no conflict of interest.

\section{ACKNOWLEDGEMENTS}

Author's Role: All authors helped to write the manuscript and have seen and approved the final version. A special thanks to Jerónimo Graf and the ICU of Clínica Alemana de Santiago.

\section{REFERENCES}

[1] Shelly MP. The humidification and filtration functions of the airways. Respir Care Clinics N Am 2006; 12: 139-48.

[2] Chikata Y, Oto J, Onodera M, Nishimura M. Humidification performance of humidifying devices for tracheostomized patients with spontaneous breathing. Respir Care 2013; 58: 1442-8.

[3] Retamal J, Castillo J, Bugedo G, Bruhn A. Airway humidification practices in Chilean intensive care units. Rev Med Chile 2012; 140: 1425-30.

[4] Gross JL, Park GR. Humidification of inspired gases during mechanical ventilation. Minerva Anestesiol 2012; 78: 496-502.

[5] Oto J, Nakataki E, Okuda N, Onodera M, Imanaka H, Nishimura M. Hygrometric properties of inspired gas and oral dryness in patients with acute respiratory failure during noninvasive ventilation. Respir Care 2014; 59: 39-45.

[6] Wood KE, Flaten AL, Backes WJ. Inspissated secretions: a lifethreatening complication of prolonged noninvasive ventilation. Respir Care 2000; 45: 491-3.

[7] Restrepo RD, Walsh BK. American Association for Respiratory Care. Humidification during invasive and noninvasive mechanical ventilation: 2012. Respir Care 2012; 57: 782-8.

[8] Haitham S, Ashry A, Modrykamien A. Humidification during mechanical ventilation in the adult patient. Biomed Res Int 2014; 2014: 715434 .

[9] Cruz C. Humidification systems in mechanical ventilation. Respiratory theraphyst opinion. Revista Teoría y praxis investigativa 2008; 3 .

[10] Shelly MP, Lloyd GM, Park GR. A review of the mechanisms and methods of humidification of inspired gases. Intensive Care Med 1988; 14: 1-9.

[11] Gheber L, Priel Z. Extraction of cilium beat parameters by the combined application of photoelectric measurements and computer simulation. Biophysical J 1997; 72: 449-62.

[12] Kilgour E, Rankin N, Ryan S, Pack R. Mucociliary function deteriorates in the clinical range of inspired air temperature and humidity. Intensive Care Med 2004; 30: 1491-4.

[13] Williams R, Rankin N, Smith T, Seakins P, Galler D. Relationship between the humidity and temperature of inspired gas and the function of the airway mucosa. Crit Care Med 1996; 24: 1920-9. 
[14] Branson RD, Gentile MA. Is humidification always necessary during noninvasive ventilation in the hospital? Respir Care 2010; 55: 209-16.

[15] Ballard ST, Inglis SK. Liquid secretion properties of airway submucosal glands. J Physiol 2004; 556: 1-10.

[16] Branson RD, Campbell RS, Chatburn RL, Covington J. AARC clinical practice guideline. Humidification during mechanical ventilation. American Association for Respiratory Care. Respir Care 1992; 37: 887-90.

[17] Rathgeber J, Kazmaier S, Penack O, Züchner K. Evaluation of heated humidifiers for use on intubated patients: a comparative study of humidifying efficiency, flow resistance, and alarm functions using a lung model. Intensive Care Med 2002; 28: 731-9.

[18] Schena E, Saccomandi P, Cappelli S, Silvestri S. Mechanical ventilation with heated humidifiers: measurements of condensed water mass within the breathing circuit according to ventilatory settings. Physiol Meas 2013; 34: 813-21.

[19] Al Ashry HS, Modrykamien AM. Humidification during mechanical ventilation in the adult patient. BioMed Res Int 2014; 2014: Article ID: 715434 .

[20] Lellouche F, Taille S, Maggiore SM, et al. Influence of ambient and ventilator output temperatures on performance of heated-wire humidifiers. Am J Respir Crit Care Med 2004; 170: 1073-79.

[21] Lellouche F, Lyazidi A, Rodriguez P, Brochard L. Condensation in inspiratory and expiratory circuits of heated wire humidifiers, evaluation of a new expiratory, "porous", circuit and of new humidification compensation systems. In: Proceedings of the $100^{\text {th }}$ International Conference of the American Thoracic Society, San Diego, Calif, USA 2005.

[22] Nishida T, Nishimura M, Fujino Y, Mashimo T. Performance of heated humidifiers with a heated wire according to ventilatory settings. J Aerosol Med 2001; 14: 43-51.

[23] Darin J, Broadwell J, MacDonell R. An evaluation of water-vapor output from four brands of unheated, prefilled bubble humidifiers. Respir Care 1982; 27: 41-50.

[24] Chalon J, Loew D, Maibranche J. Effects of dry anesthetic gases on tracheobronchial ciliated epithelium. Anesthesiology 1972; 37: 338-43.

[25] Villafane MC, Cinnella G, Lofaso F, et al. Gradual reduction of endotracheal tube diameter during mechanical ventilation via different humidification devices. Anesthesiology 1996; 85: 134149

[26] Chatburn RL, Primiano FP. A rational basis for humidity therapy. Resp Care 1987; 32: 249-54.

[27] Mapleson WW, Morgan JG, Hillard EK. Assessment of condenserhumidifiers with special reference to a multiple gauze model. $\mathrm{Br}$ Med J 1963; 1: 300-5.

[28] Hingorani BK. The resistance to airflow of tracheostomy tubes, connections, and heat and moisture exchangers. Br J Anaesth 1965; 37: 454-63.

[29] Lellouche F, Taille S, Lefrancois F, et al. Humidification performance of 48 passive airway humidifiers: comparison with manufacturer data. Chest 2009; 135: 276-86.

[30] Martin C, Perrin G, Gevaudan MJ, Saux P, Gouin F. Heat and moisture exchangers and vaporizing humidifiers in the intensive care unit. Chest 1990; 97: 144-49.

[31] Branson RD. Humidification of respired gases during mechanical ventilation: mechanical considerations. Respir Care Clin N Am 2006; 12: 253-61

[32] Chen TY, Chen KT, Chang DP, Yeh FC, Chang CL. The effect of heated humidifier in the prevention of intra-operative hypothermia. Anaesthesiology 1994; 32: 27-30.

[33] Suliman HS1, Fecura SE, Baskin J, Kalns JE. Laboratory evaluation of 10 heat and moisture exchangers using simulated aeromedical evacuation conditions. Mil Med 2011; 176: 656-9.

[34] Standardization of humidifiers for mechanical use: general requirements for humidification systems. International Organization for Standardization. $3^{\text {rd }}$ ed. ISO 2007; p. 8185.

[35] van den Boer C, Nuller SH, Vincent AD, van den Brekel MW, Hilgers FJ. Ex vivo assessment and validation of water exchange performance of 23 heat and moisture exchangers for laryngectomized patients. Respir Care 2014: 59: 1161-71.

[36] Lemmens HJ, Brock-Utne JG. Heat-and-moisture exchanger devices: are they doing whatthey are supposed to do? Anesth Analg 2004; $98: 382-5$
[37] Ricard JD, Cook D, Griffith L, Brochard L. Physicians' attitude to use heat and moisture exchangers or heated humidifiers: a FrancoCanadian survey. Intensive Care Med 2002; 28: 719-25.

[38] Branson R, Gomaa D, Rodriquez D. Management of the artificial airway. Respir Care 2014; 59: 974-89.

[39] Branson RD. The effects of inadequate humidity. Respir Care Clin N Am 1998; 4: 199-214.

[40] Lellouche F, Qader S, Taillé S, Lyazidi A, Brochard L. Influence of ambient temperature and minute ventilation on passive and active heat and moisture exchangers. Respir Care 2014; 59: 637-43.

[41] Wilkes AR. Humidification in intensive care: are we there yet? Respir Care 2014; 59: 790-3

[42] Villafane MC, Cinnella G, Lofaso F, et al. Gradual reduction of endotracheal tube diameter during mechanical ventilation via different humidification devices. Anesthesiology 1996; 85: 1341-9.

[43] Mechanical ventilation protocol summary. ARDSNet (NIH NHLBI ARDS) Clinical Network [Accessed: January 24, 2014].

[44] Pelosi P, Solca M, Ravagnan I, Tubiolo D, Ferrario L, Gattinoni L. Effects of heat and moisture exchangers on minute ventilation, ventilator drive, and work of breathing during pressure-support ventilation in acute respiratory failure. Crit Care Med 1996; 24:1184-8

[45] Morán I, Bellapart J, Vari A, Mancebo J. Heat and moisture exchangers and heated humidifiers in acute lung injury/acute respiratory distress syndrome patients: effects on respiratory mechanics and gas exchange. Intensive Care Med 2006; 32: 52431.

[46] Prat G, Renault A, Tonnelier J. et al. Influence of the humidification device during acute respiratory distress syndrome. Intensive Care Med 2003; 29: 2211-5.

[47] Donlan RM. Biofilms: Microbial life on surfaces. Emerg Infect Dis 2002; 8: 881-90.

[48] Thomas JG, Nakaishi LA. Managing the complexity of a dynamic biofilm. J Am Dent Assoc 2006; 137: 10-15.

[49] Danin PE, Girou E, Legrand P, et al. Description and microbiology of endotracheal tube biofilmin mechanically ventilated patients. Respir Care 2015; 60: 21-9

[50] Coppadoro A, Bellani G, Bronco A, et al. Measurement of endotracheal tube secretions volume by micro computed tomography (MicroCT) scan: an experimental and clinical study. BMC Anesthesiol 2014; 14: 22.

[51] Branson RD. The ventilator circuit and ventilator-associated pneumonia. Respir Care 2005; 50: 774-85

[52] Lee Y, Kim H. The effects of heated humidified gases on body temperature and shivering in patients under general anesthesia. Int $\mathrm{J}$ Bio-Sci Bio-Technol 2013; 5: 61-72.

[53] Siempos I, Vardakas K, Kopterides P, and Falagas M. Impact of passive humidification on clinical outcomes of mechanically ventilated patients: a meta-analysis of randomized controlled trials. Crit Care Med 2007; 35: 2843-51.

[54] Thomachot L, Viviand X, Arnaud S, Boisson C, Martin C. Comparing two heat and moisture exchangers, one hydrophobic and one hygroscopic, on humidifying efficacy and the rate of nosocomial pneumonia. Chest 1998; 114: 1383-89.

[55] Kola A, Eckmanns T, Gastmeier P. Efficacy of heat and moisture exchangersin preventing ventilator-associated pneumonia: metaanalysis of randomized controlled trials. Intensive Care Med 2005; 31: 5-11.

[56] Lorente L, Lecuona M, Jiménez A, Mora M, Sierra A. Ventilatorassociated pneumonia using a heated humidifier or a heat and moisture exchanger: a randomized controlled trial. Crit Care 2006; 10: 116.

[57] Ilias I. Impact of passive humidification on clinical outcomes of mechanically ventilated patients: a meta-analysis of randomized controlled trials. Crit Care Med 2007; 35: 2843-51.

[58] Auxiliadora-Martins M, Menegueti M, Nicolini E, et al. Effect of heat and moisture exchangers on the prevention of ventilator associated pneumonia in critically ill patients. Braz J Med Biol Res 2012; 45: 1295-300

[59] Menegueti MG, Auxiliadora-Martins M, Nunes AA. Effectivenes of heat and moisture exchangers in preventing ventilator associated pneumonia in critically ill patients: a meta-analysis. BMC Anesthesiology 2014; 14: 115

[60] Hill NS, Brennan J, Garpestad E, Nava S. Noninvasive ventilation in acute respiratory failure. Crit Care Med 2007; 35: 2402-7. 
[61] Hess D. Patient-ventilator interaction during noninvasive ventilation. Respir Care 2011; 56: 153-65.

[62] Lellouche F, L'Her E, Abroug F, et al. Impact of the humidification device on intubation rate during noninvasive ventilation with ICU ventilators: results of a multicenter randomized controlled trial. Intensive Care Med 2014; 40: 211-9.

[63] Kushida CA, Littner MR, Hirshkowitz M, et al. Practice parameters for the use of continuous and bilevel positive airway pressure devices to treat adult patients with sleep related breathing disorders. Am Acad Sleep Med 2006; 29: 375-80.

[64] Esquinas A, Scala R, Soroksky A, et al. Clinical review: humidifiers during non-invasive ventilation key topics and practical implications. Crit Care 2012; 16: 203.

[65] Lellouche F, Maggiore SM, Deye N, et al. Effect of the humidification device on the work of breathing during noni nvasive ventilation. Intensive Care Med 2002; 28: 1582-9.

[66] Oto J, Nakataki E, Okuda N, Onodera M, Imanaka H, Nishimura $\mathrm{M}$. Hygrometric properties of inspired gas and oral dryness in patients with acute respiratory failure during non-invasive ventilation. Respir Care 2014; 59: 39-45.

[67] Mador MJ, Krauza M, Pervez A, Pierce D, Braun M. Effect of heated humidification on compliance and quality of life in patients with sleep apnea using nasal continuous positive airway pressure. Chest 2005; 128: 2151-8.

[68] Ohki M, Usui N, Kanazawa H, et al. Relationship between oral breathing and nasal obstruction in patients with obstructive sleep apnea. Acta Otolaryngol Suppl 1996; 523: 228-30.

[69] Martins de Araujo MT, Barros S, Corral E, Fleury B. Heated humidification or face mask to prevent upper airway dryness during continuous positive airway pressure therapy. Chest 2000; 117: $142-7$.

[70] Hess DR. Noninvasive ventilation for acute respiratory failure. Respir Care 2013; 58: 950-72.

[71] Jaber S, Chanques G, Matecki S, et al. Comparison of the effects of heat and moisture exchangers and heated humidifiers on ventilation and gas exchange during non-invasive ventilation. Intensive Care Med 2002; 28: 1590-4.

[72] Mas A, Masip J. Noninvasive ventilation in acute respiratory failure. Int J Chron Obstruct Pulmon Dis 2014; 9: 837-52.

[73] Lellouche F, Pignataro C, Maggiore SM, et al. Short-term effects of humidification devices on respiratory pattern and arterial blood gases during noninvasive ventilation. Respir Care 2012; 57: 1879886.

(c) Cerpa et al.; Licensee Bentham Open.

This is an open access article licensed under the terms of the Creative Commons Attribution Non-Commercial License (http://creativecommons.org/licenses/by-nc/3.0/) which permits unrestricted, non-commercial use, distribution and reproduction in any medium, provided the work is properly cited. 